Annuaire du Collège de France 2017-2018

\title{
Étude de la création littéraire en langue anglaise (2002-2008)
}

\section{Michael Edwards}

\section{(2) OpenEdition \\ 1 Journals}

\section{Édition électronique}

URL : https://journals.openedition.org/annuaire-cdf/16078

DOI : 10.4000/annuaire-cdf. 16078

ISBN : 978-2-7226-0572-5

ISSN : 2109-9227

\section{Éditeur}

Collège de France

Édition imprimée

Date de publication : 30 décembre 2020

Pagination : 636-637

ISBN : 978-2-7226-0516-9

ISSN : 0069-5580

\section{Référence électronique}

Michael Edwards, «Étude de la création littéraire en langue anglaise (2002-2008) », L'annuaire du Collège de France [En ligne], 118 | 2020, mis en ligne le 01 avril 2021, consulté le 22 août 2022. URL http://journals.openedition.org/annuaire-cdf/16078; DOI : https://doi.org/10.4000/annuaire-cdf. 16078 


\title{
ÉTUDE DE LA CRÉATION LITTÉRAIRE EN LANGUE ANGLAISE (2002-2008)
}

\author{
Michael EDWARDS
}

Membre de l'Académie française, professeur émérite

\section{RECHERCHES}

Mon travail principal a consisté à faire avancer les deux livres commencés l'année dernière, que j'aurais pu terminer sans la présence d'autres obligations. Trois chapitres se sont ajoutés à Pour un christianisme intempestif (titre provisoire). J'ai fini d'écrire "Je suis la vérité », chapitre clé sur cette déclaration étonnante de Jésus qui transcende la capacité de la philosophie et qui demande une pratique de l'existence tout à fait inouïe. "Cherchez et vous trouverez » étudie une autre de ses déclarations inattendues qui, comme de nombreux appels dans les Évangiles, fait suivre l'impératif par un verbe au futur comme une sorte de garantie de succès, et incite à réfléchir de nouveau en dehors des normes de la pensée. «L'Art, l'étrange expérience », qui sera d'abord la conférence d'introduction à un colloque de l'Académie catholique de France, cherche à redéfinir les rapports entre l'art et le christianisme, en constatant que la Bible est déjà un ouvrage littéraire et que l'art, universellement désiré, porte l'espérance en lui, par ses façons d'exister qui suggèrent toujours un réel renouvelé, mais s'efface devant le cosmos en tant que création, qui révèle, au-delà de la beauté et l'expérience esthétique, une mystérieuse «gloire ». Le livre qui a donné naissance à ce projet, Bible et poésie, a été le sujet d'un colloque en mai 2018 à l'université d'Oxford.

L'autre livre, un recueil de poèmes en anglais, a progressé jusqu' au poème 47.

Mes travaux pour l'Académie française ont été plus nombreux que d'habitude. J'ai écrit la « Réponse » au « Discours de réception » de notre collègue Michel Zink, qui constitue une analyse détaillée de son œuvre. Pour la rentrée des Cinq Académies, dont le thème cette année est «L'Étonnement », j' ai étudié, à travers des passages de la Commedia de Dante, d'Iphigénie de Racine et de L'Origine des espèces de Darwin, le pouvoir de l'étonnement de nous projeter hors du connu vers un insoupçonné salutaire. J'ai publié aussi des bloc-notes sur la perte de certaines voyelles dans le français contemporain et sur l'intérêt d'introduire le mot maloproprisme, et composé un «Hommage à Jean d'Ormesson» et le « Discours sur les prix littéraires. »

J'ai accepté en outre d'écrire des textes sur Bernard de Fallois, sur Claudel et le Japon et, pour l'université de Gdansk, sur la poétique chrétienne.

\section{PUBLICATIONS}

EDWARDS M., In a Wide Bewilderment of Quiet (poésies, aquarelles de Greg Wyatt), New York, Thornwillow Press, 2018. 
Edwards M., Capitales (poésies, dessins de Pascale Hémery), Frameries, Éditions Bruno Robbe, 2018.

EdWARDS M., « At the Brasserie Lipp » (poésie), PN Review, nº 237, 2017, p. 18-21.

EDWARDS M., «L'Europe ? », Po\&sie, no 160-161, 2017, p. 160-163.

EDWARDS M., « Discours sur les prix littéraires », Académie française, 2017, p. 5-28.

EDWARDS M., « Hommage à M. Jean d'Ormesson », Académie française, 2017, p. 5-8.

EdWARds M., «L'Étrangeté du mal », Philosophie magazine, hors-série no 36, 2018, p. 123129.

EDWARDS M., «De chozzes et d'ottres », Bloc-notes, Académie française, 2018.

EDWARDS M., «Des paroles (peu) nombreuses », Communio, no 256, 2018, p. 91-100.

EDWARDS M., « Malapropisme », Bloc-notes, Académie française, 2018.

EDwards M., «L'Antiquité vécue », in J. BouINEAU (dir.), L'Avenir se prépare de loin, Paris, Les Belles Lettres, 2018, p. 93-97. 